\title{
Ensaio sobre a impunidade: os crimes contra a humanidade cometidos no Brasil ${ }^{*}$
}

\author{
Essay on impunity: the crimes against \\ humanity committed in Brazil
}

Silvia Menicucci O. S. Apolinário ${ }^{1}$

Lúcia Elena Arantes Ferreira Bastos²
Recebido em: 16/02/2016.

Aprovado em: 18/02/2016.

1 Doutora e Mestre em Direito Internacional pela Faculdade de Direito da Universidade de São Paulo. Professora do curso de Relações Internacionais do Centro Universitário de Brasília (UniCEUB).

2 Doutora em Direito Internacional pela Faculdade de Direito da Universidade de São Paulo. Pós-Doutora pelo Núcleo de Estudos da Violência da Universidade de São Paulo (NEV/ USP).

\section{Resumo}

Ao lado das normas de proteção da pessoa humana, desenvolveu-se o Direito Internacional Penal, que definiu, entre outros, os crimes contra a humanidade. Essa institucionalização permite a discussão de momentos do passado brasileiro - o período colonial e imperial, o período das frentes de expansão e pioneira do interior brasileiro, e o regime militar -, marcados pela prática de crimes contra a humanidade, incluindo o genocídio, no contexto do massacre dos povos indígenas, a desumanização dos negros na migração forçada, e a repressão militar. A impunidade é característica comum dos crimes cometidos em momentos e condições diferentes da história brasileira. Este ensaio, ao trabalhar com as noções de tempo e Direito, visa explorar a interface dos debates surgidos nos âmbitos internacional e nacional do encontro entre o passado ainda vivo e as chances de se buscar a justiça nos tribunais nacionais e internacionais, em especial quanto aos crimes cometidos no regime militar, e outras diferentes formas de reparação.

Palavras-chave: Passado. Crimes contra a humanidade. Genocídio. Escravidão. Tráfico humano. Regime militar. Anistia. Justiça.

\begin{abstract}
The International Criminal Law developed beside the standards of protection of the human person, defining, among others, the crimes against humanity. This institutionalization allows the discussion of certain moments of the Brazilian past marked by the commission of crimes against humanity, including the genocide of indigenous peoples, the dehumanization of African people and their descendants in forced migration, and the military repression. The referred moments are the colonial and imperial period, the period of the fronts of expansion of the Brazilian up-country, and the military regime. Impunity is the common characteristic of the crimes committed at different times and conditions of the Brazilian history. This essay aims to explore the interface of the debates that emerged in the international and national levels related to the encounter between the still living past and the chance to seek justice in national and international courts, in particular with regard to crimes committed during the military regime, and other various forms of compensation.
\end{abstract}

Keywords: Past. Crimes against humanity. Genocide. Slavery. Human trafficking. Military regime. Amnesty. Justice. 


\section{Introdução}

Anúncio veiculado em 1876 no jornal "O Estado de São Paulo":

Atenção. Aos possuidores de escravos: Precisa-se saber quem é o atual possuidor do escravo Manoel, crioulo, com o apelido Macota; foi escravo do major José Mascarenhas Galter, do Paty do Alferes, Província do Rio, é filho da escrava Presciliana e irmão de Floripe, pardo, e Apolinaria, cabra. Foi há mais de 15 anos vendido em Vassouras por Francisco José da Silva a um negociante de escravos de Queimados, que o vendeu na cidade de Campinas. Quem possuir o dito escravo, pode dirigir-se aos Srs. Siqueira \& Rosas, de Santos, ou a Marcondes Machado \& Comp., rua Municipal número 1 côrte, que o antigo senhor compra e paga bem, por ter dele necessidade. ${ }^{3}$

Trecho do Relatório Figueiredo, escrito em 1967, sobre a atuação do Serviço de Proteção do Índio (SPI) ${ }^{4}$ :

A fertilidade de sua cruenta história registra até crucificação, os castigos físicos eram considerados fato natural nos postos indígenas. [...] O "tronco" era, todavia, o mais encontradiço de todos os castigos, consistia na trituração do tornozelo da vítima, colocado entre duas estacas enterradas juntas em ângulo agudo. As extremidades, ligadas por roldanas, eram aproximadas, lenta e continuamente.

Trecho noticiado, no dia 27 de agosto de 2015, pelo jornal "O Globo", ao noticiar que o Ministério Público Federal (MPF) ofereceu mais uma denúncia contra o coronel reformado Carlos Alberto Brilhante Ustra por crimes cometidos durante a ditadura militar:

O operário Carlos Nicolau Danielli integrava a cúpula do Partido Comunista do Brasil (PCdoB). Em 28 de dezembro de 1972, foi detido e levado para o DOI, onde foi torturado durante três dias. Segundo relatos de outros presos, Danielli estava, já no segundo dia, próximo da morte, com o abdómen inchado, olhar estático, sangrando pelos ouvidos e pela boca, sem

O ESCRAVO Macota. O Estado de São Paulo, São Paulo, p. 3-4, 16 nov. 1876.

O Relatório foi resultado da investigação, feita em plena ditadura, a pedido do então Ministro do Interior, Albuquerque Lima, em 1967, que abrangeu uma expedição que percorreu mais de 16 mil quilômetros, entrevistou dezenas de agentes do SPI e visitou mais de 130 postos indígenas. Órgão criado em 1910, quando várias frentes de expansão avançavam para o interior do país, o SPI era ligado ao Ministério do Interior e funcionou até 1967, quando foi substituído pela Fundação Nacional do Índio (FUNAI). BRASIL. Ministério Público Federal. Relatório Figueiredo. Disponivel em: <http://6ccr.pgr.mpf.mp.br/institucional/ grupos-de-trabalho/gt_crimes_ditadura/relatorio-figueiredo >. Acesso em: 28 ago. 2015. condições de se manter de pé. Morreu no dia 30. Danielli foi enterrado como indigente no cemitério de Perus, em São Paulo. O dirigente comunista foi uma das 37 pessoas assassinadas no DOI durante o período em que Ustra esteve à frente do destacamento, de 1970 a 1974. Sob o comando do então major, Gravina e Calandra conduziram várias ações de sequestro e sessões de tortura contra opositores do regime militar. $^{5}$

Os trechos acima remetem a momentos diferentes do passado brasileiro: (i) o período colonial até pouco antes do final do Império, ou seja, aos crimes infligidos contra os povos africanos, forçados à migração e utilizados como mão de obra escrava, que também tiveram os povos indígenas entre suas vítimas; (ii) o período das frentes de expansão e pioneira do interior brasileiro; e (iii) a repressão militar que acompanhou os regimes não democráticos instaurados em muitos Estados da região. Os contextos e as vítimas são diferentes, mas todos têm em comum a impunidade pelos crimes cometidos, considerados crimes contra a humanidade, e traços tão marcantes, que suas heranças são até hoje sentidas e vividas.

A expressão "crime contra a humanidade" foi utilizada pela primeira vez em 1915, numa declaração em que França, Grã-Bretanha e Rússia condenaram o massacre dos armênios pelos turcos. Em 1946, ocorreu sua primeira menção em um instrumento jurídico $\square$ no artigo $6^{\circ}$ dos estatutos do Tribunal Militar Internacional de Nuremberg. A definição jurídica aprimorou-se ao longo da história e do desenvolvimento do Direito Internacional Penal, por meio da instituição, pelo Conselho de Segurança da ONU, dos tribunais ad hoc para Antiga Iugoslávia (Resolução 827/1993) e Ruanda (Resolução 955/1994), e pelo estabelecimento do Tribunal Penal Internacional (TPI), por meio do Tratado de Roma de 1998 ("Estatuto do TPI").

De acordo com o artigo $7^{\circ}$ do Estatuto do TPI, os crimes contra a humanidade são qualquer ato praticado como parte de um ataque generalizado ou sistemático contra uma população civil e com conhecimento de tal ataque, incluindo: (a) homicídio; (b) extermínio; (c) escravidão; (d) deportação ou transferência forçada de populações; (e) encarceramento ou privação grave da liberdade física em violação a normas fundamentais de Direito Internacional; (f) tortura; (g) estupro, escravidão

MPF denuncia coronel Ustra por morte de militante comunista em 1972. O Globo, Rio de Janeiro, 27 ago. 2015. Disponível em: <http://oglobo.globo.com/brasil/mpf-denuncia-coronel-ustra-por-morte-de-militante-comunista-em-1972-17321904>. Acesso em: 22 mar. 2016. 
sexual, prostituição compulsória, gravidez imposta, esterilização forçada ou outros abusos sexuais graves; (h) perseguição de um grupo ou coletividade com identidade própria, por motivos políticos, raciais, nacionais, étnicos, culturais ou religiosos; (i) desaparecimento de pessoas; (j) apartheid; e (k) outras práticas que causem grande sofrimento ou atentem contra a integridade física ou saúde mental das pessoas.

O crime de genocídio aparece como uma espécie particular do gênero crime contra a humanidade. As vítimas do genocídio não são visadas individualmente, mas como representantes de um grupo ou uma parte de um grupo da população destinada, coletivamente, ao desaparecimento. Tal como a Convenção para Prevenção e a Repressão do Crime de Genocídio de 1948, o Estatuto do TPI define, no artigo $6^{\circ}$, o crime de genocídio como qualquer ato praticado com intenção de destruir total ou parcialmente um grupo nacional, étnico, racial ou religioso, compreendendo: (a) matar membros do grupo; (b) causar lesão grave à integridade física ou mental de membros do grupo; (c) submeter intencionalmente o grupo a condiçõos de existência capaz de lhes ocasionar a destruição física, total ou parcial; (d) adotar medidas destinadas a impedir nascimentos no seio do grupo; e (e) efetuar a transferência forçada de crianças do grupo para outro grupo.

A adoção de normas internacionais, que tornaram puníveis certas condutas somente em momento histórico bem posterior a sua ocorrência (no caso do período colonial e de parte do período das frentes de expansão e pioneira) ou a não condenação dessas condutas (no caso da repressão militar e das atrocidades cometidas contra os povos indígenas), quando muitas delas configuram claras violações ao Direito Internacional dos Direitos Humanos (DIDH) vigente, pautam as indagações desse ensaio.

Por que a necessidade de punir condutas antes perpetradas e não condenadas foi considerada somente após o holocausto? Seria o fato de que, pela primeira vez, o europeu teria assassinado, torturado e exterminado seus iguais - os brancos? ${ }^{6}$ Ou haveria outra causa, relacionada às fontes do Direito Internacional ou àqueles

\footnotetext{
"O que o burguês supercristão do século XX não perdoa a Hitler não é o crime em si, não é a humilhação do homem em si, mas o crime contra o homem branco [...] de ter aplicado à Europa procedimentos colonialistas que até então só abrangiam os árabes, os cules da Índia e os negros da África." CÉSAIRE, Aimé. Discours sur le colonialisme. Paris: Présence Africaine, 1995.
}

que elaboram suas fontes, os Estados? Sugere-se que o período pós-Segunda Guerra Mundial deu início a uma reconstrução dos direitos humanos ${ }^{7}$ e, em paralelo, a uma mudança no Direito Internacional, em que passaram a coexistir dois paradigmas ainda que em desequilíbrio de forças: o centrado no Estado, para o qual ainda pende o prato da balança, e um outro centrado no indivíduo.

Todavia, por mais que a proteção internacional da pessoa humana tenha se desenvolvido, ainda há forças que impedem a punição de crimes contra a humanidade. Atos ocorridos no passado retornam à discussão em um contexto de maior normatização internacional e nacional, tais como a Lei de Anistia no Brasil. Assim, perguntamos: a sociedade brasileira é capaz de ratificar os tratados, internalizando as normas de proteção da pessoa humana e da responsabilização por crimes contra a humanidade, mas é incapaz de puni-los? Diferentemente do passado colonial e imperial, é inegável a existência, nos dias atuais, de normas que obrigam o Brasil interna e internacionalmente a julgar e, se for o caso, punir crimes dessa natureza.

A juridicização dos crimes contra a humanidade permitiu a elevação da responsabilidade penal dos indivíduos a nível internacional, assim como a construção da noção de jurisdição universal ${ }^{8}$. Além disso, o desenvolvimento das normas de Direito Internacional Penal levou ao reconhecimento dos crimes contra a humanidade, incluindo o genocídio, como imprescritíveis, independentemente da data em que tenham sido cometidos ${ }^{9}$.

LAFER, Celso. A reconstrução dos direitos humanos: um diálogo com o pensamento de Hannah Arendt. São Paulo: Companhia das Letras, 1988.

8 A extradição de Ricardo Miguel Cavallo, do México para a Espanha, pela acusação de crimes cometidos durante a "guerra suja" na Argentina marca os esforços de justiça universal; bem como a extradição de Alberto Fujimori, do Chile para o Peru, em 2007. No mesmo sentido, foi o caso das vítimas chilenas de Pinochet na Espanha. Ambos foram indiciados com base no princípio de jurisdição universal: a norma de que todo Estado tem interesse em levar à justiça os perpetradores de crimes internacionais, independentemente do local onde o crime foi cometido e da nacionalidade dos perpetradores ou das vítimas. HUMAN RIGHTS WATCH. Historic moment in the fight to ensure there are no safe havens for mass killers. June 30, 2003. Available in: <https://www.hrw.org/news/2003/06/30/ historic-moment-fight-ensure-there-are-no-safe-havensmass-killers>. Access: Mar. 22, 2016.

9 ORGANIZAÇÃO DAS NAÇÕES UNIDAS. Convenção sobre a Imprescritibilidade dos Crimes de Guerra e dos Crimes Contra a Humanidade. 1968. Disponível em: <http://www.direitoshumanos.usp.br/index.php/ Sistema-Global.-Declara\%C3\%A7\%C3\%B5es-e-Trata- 
As discussões internacionais a respeito de crimes contra a humanidade permitiram a discussão ou rediscussão de temas importantes. Entre tais temas, elencam-se as reparações pelas violações cometidas, o reconhecimento jurídico do ocorrido, os pedidos de desculpas formais, a imprescritibilidade, a impunidade, a revisão de leis de anistia, obediência civil ou ponto final, a abertura de arquivos, o direito à memória, o direito à verdade, $\mathrm{o}$ direito ao luto, a revisão da história e de livros didáticos.

$O$ resgate de temas do passado brasileiro, vinculado à abordagem dos crimes contra a humanidade, é importante para a compreensão das consequências de tais crimes, que perduram em nossas sociedades na forma de discriminação racial, nas desigualdades socioeconômicas $^{10}$, e na descrença na justiça minada pela impunidade.

\section{Os crimes históricos cometidos no colonialis- mo e a herança de sua impunidade na socie- dade brasileira}

A história da humanidade está repleta de episódios de genocídio, escravidão, tortura, expulsões, que se mantém vivos na memória, constituindo crimes históricos. A própria existência e as fronteiras dos Estados modernos são resultados dos atos e omissões passadas, que hoje certamente seriam considerados inadmissíveis de acordo com o Direito Internacional e muitas constituições nacionais. Os crimes históricos são geralmente observados como alcançando grupos inteiros, minorias desfavorecidas ou populações estrangeiras, e são diferentes dos casos individuais ou isolados, uma vez que se referem a populações que foram mortas, excluídas ou sujeitas a discriminações por outros grupos que, por meio de privilégios e opressões, enriqueceram-se e/ou conquistaram poder, território e impuseram sua dominação. ${ }^{11}$

dos-Internacionais-de-Prote\%C3\%A7\%C3\%A3o/convencao-sobre-a-imprescritibilidade-dos-crimes-de-guerra-e-dos-crimes-contra-a-humanidade.html>. Acesso em: 22 mar. 2016.

10 Os regimes democráticos que julgaram aqueles que violaram os direitos humanos, em crimes como tortura, assassinato, prisão sem o devido processo legal, desaparecimento de pessoas ou genocídio, tiveram uma melhora significativa na preservação dos direitos básicos de seu povo, ao passo em que naqueles Estados em que não houve ainda, punições, a situação foi inversa.. SIKKINK, Kathryn. Human rights, principled issue-networks, and sovereignty in Latin America. International Organization, Cambridge, v. 47, n. 3, p. 411-441, Summer, 1993.
Enquadram-se como crimes históricos, portanto, o massacre dos povos indígenas e a solução africana, que concretizaram um sistema de desumanização, repleto de crimes indescritíveis. Torturas, discriminação racial, deslocamentos forçados, execuções sumárias, abusos sexuais, extermínios, e a maior deportação de seres humanos testemunhada pela história - o tráfico negreiro - , que perdurou durante séculos, compõem a miríade de crimes perpetrados em face dos povos bárbaros pelos povos civilizados, ${ }^{12}$ que restaram impunes. Essa dualidade bárbaros e civilizados - ainda hoje persiste registrada em tratados internacionais, como a própria Carta da $\mathrm{ONU}^{13}$. A missão civilizatória e a infantilização das raças justificaram ou omitiram muitos dos crimes perpetrados em face dos ameríndios e dos negros africanos.

De fato, o Direito Internacional iniciou sua institucionalização justamente na época das "descobertas", da reformulação da racionalidade antiga, do desenvolvimento da ciência e sua aplicação tecnológica e da emergência de uma nova teoria do Estado. O Direito Internacional foi um aliado das potências colonizadoras, legitimando a ocupação de terras e as violações cometidas, com base em alegadas razões humanitárias ou com o alegado intuito de se levar o desenvolvimento aos povos atrasados.

$\mathrm{Na}$ prática, o prolongamento da experiência do horror durante mais de três séculos condicionou, em larga escala, a sistematização teórica das desigualdades, entre outras a desigualdade racial, cujas consequências marcaram toda o período subsequente da história brasileira, tal como o período das frentes de expansão e pioneira. Para além do número de indígenas exterminados e negros desumanizados, o comportamento adotado pelos conquistadores e pela elite que lhes seguiu teve impactos que perduraram em nossa sociedade. Milhões de mulheres, crianças e homens africanos, arrancados da sua terra e deportados para as Américas, foram sistematicamente excluídos da espécie humana e reduzidos à categoria de bem móvel ou sub-humano. Os indígenas sobreviventes, despojados das suas terras, foram repelidos para as reservas.

for historical injustices. Netherlands International Law Review, Cambridge, v. 50, p. 289-325, 2003.

12 TODOROV, Tzvetan. A conquista da América: a questão do outro. Tradução Beatriz Perrone-Moisés. 3. ed. São Paulo: M. Fontes, 2003.

13 O capítulo XI da Carta das Nações Unidas dispõe a respeito da declaração relativa a territórios sem governo próprio e reafirma a missão civilizatória e a tese da incapacidade no artigo 73. 
A situação de impunidade de que se beneficiavam os conquistadores favoreceu o aparecimento de práticas bastante inquietantes e do preconceito arraigado em nossas sociedades. Tem-se por hábito ignorar que, graças à racionalização da escravatura no universo da América, a superioridade da raça branca e a inferioridade dos negros e índios se tornaram um axioma profundamente enraizado na cultura ocidental.

Essa herança perniciosa do domínio colonial europeu, combinada com os efeitos nefastos da mania das Luzes de tudo ordenar, hierarquizar e classificar, estimulou a criação de uma cultura favorável ou, pelo menos, tolerante ao extermínio de grupos considerados inferiores. Estas são, como apontou Arendt, as bases do imperialismo e do regime de terror posteriormente infligido na Alemanha e na Rússia ${ }^{14}$.

Interessante observar que a origem da abordagem crítica ao colonialismo em âmbito internacional político-jurídico não se encontra na iniciativa dos países da América, mas sim dos países asiáticos e africanos, que alcançaram sua independência mais tardiamente e levaram o tema dos direitos dos povos, em especial do direito à autodeterminação e do direito ao desenvolvimento à ONU nas décadas de 1960, 1970, 1980. Na América Latina, destacaram-se as construções teóricas econômicas de desenvolvimento, principalmente no âmbito da Comissão Econômica para América Latina e Caribe (CEPAL). Os direitos dos povos indígenas também foram elevados aos foros internacionais, todavia, com resultados limitados, que provam à persistência da força do paradigma do

14 A respeito da raça como um mecanismo de organização política e domínio dos povos estrangeiros durante o Imperialismo, Arendt nos lembra criticamente que: "A raça foi uma tentativa de explicar a existência de seres humanos que ficavam à margem da compreensão dos europeus, e cujas formas e feições de tal forma assustavam e humilhavam os homens brancos, imigrantes ou conquistadores, que eles não desejavam mais pertencer à mesma comum espécie humana [...] Dessa ideia resultaram os mais terríveis massacres da história: o extermínio das tribos hotentotes pelos bôeres, as selvagens matanças de Carl Peters no Sudeste Africano Alemão [...] Lorde Cromer, que no Egito passou de mero chargé d'affaires britânico a burocrata imperialista, não teria sonhado em misturar administração com massacre ("massacres administrativos", como Carthill francamente os chamou quarenta anos mais tarde), do mesmo modo que os racistas fanáticos da África do Sul jamais pensaram em organizar massacres com o fito de estabelecer comunidades políticas circunscritas e racionais (como os nazistas fizeram nos campos de extermínio)". ARENDT, Hannah. Origens do totalitarismo. São Paulo: Companhia das Letras, 1989. p. 215-216.
Estado. Assim, as reclamações dos povos indígenas acabaram sendo feitas no âmbito dos próprios Estados. ${ }^{15}$

De fato, a maioria dos países da América tornou-se independente no século XIX. As classes dirigentes desses países, chegadas ao poder na sequência de guerras de independência, identificaram-se com o seu antepassado branco; adotaram os métodos de extermínio de indígenas herdados da colonização, por exemplo, a Campaña del Desierto na Argentina, em 1834, e os fatos narrados no Relatório Figueiredo. Depois de 45 anos desaparecido, o Relatório Figueiredo, que apurou matanças de comunidades inteiras, torturas e toda sorte de crueldades praticadas contra indígenas, principalmente por latifundiários e funcionários do extinto SPI, criado em 1910, ressurgiu em abril de 2013. Supostamente eliminado em um incêndio no Ministério da Agricultura, ele foi encontrado no Museu do Índio, no Rio de Janeiro. Entre denúncias de caçadas humanas promovidas com metralhadoras e dinamites atiradas de aviões, inoculações propositais de varíola em povoados isolados e doações de açúcar misturado a estricnina, o texto, redigido pelo então procurador Jader de Figueiredo Correia, foi entregue à Comissão da Verdade.

Portanto, a independência não deu voz aos povos outrora desumanizados. O discurso no âmbito internacional retorna somente no século XX-XXI na sombra da discussão da autodeterminação dos povos e da discriminação racial. O passado se repete e a impunidade permite a repetição de atos desumanos.

No âmbito da ONU, na declaração de princípios, adotada ao final da Conferência Mundial contra o Racismo, a Xenofobia, a Discriminação e a Intolerância, realizada na cidade de Durban (África do Sul), entre 31 de agosto e 7 de setembro de $2001^{16}$, houve um acordo a

15 A título de ilustração, vale lembrar que, nos Estados Unidos, em 1946, foi instituída a Indian Claims Commission, que tinha poderes para tratar as violações causadas às propriedades indígenas; em 1971, o Alaska Native Claims Settlement Act garantiu aos índios daquela região recompensas financeiras assim como terras, e posteriormente, em 1990, uma lei federal americana ordenou a restituição dos restos mortais de índios americanos, assim como artefatos funerários aos seus descendentes. SHELTON, Dinah. The world of atonement: reparations for historical injustices. Netherlands International Law Review, Cambridge, v. 50, p. 289-325, 2003.

16 Doc. NU: A/CONF.189/12. UNITED NATIONS. Report of the World Conference against Racism, Racial Discrimination, Xenophobia and Related Intolerance. Durban, Aug./ Sept. 2001. Available at: <http://www.un.org/WCAR/ aconf189_12.pdf>. Access: Mar. 22, 2016. 
respeito de fatos do passado, nos seus $\$ \$ 13-15$, conforme segue: (i) o reconhecimento de que a escravidão e o tráfico de escravos (tráfico transatlântico, empreendido pelos europeis) são crimes contra a humanidade e deveriam sempre ter sido assim considerados, e que estão entre as fontes de racismo e discriminação; (ii) o colonialismo levou ao racismo, e o sofrimento causado pelo colonialismo foi reconhecido; e (iii) o apartheid e o genocídio são considerados crimes contra a humanidade.

Na Conferência de Durban, alguns Estados tomaram a iniciativa de se arrepender, expressar remorso ou pedir desculpas ${ }^{17}$. A declaração registrou ainda o pedido àqueles que não contribuíram para restaurar a dignidade das vítimas que encontrassem caminhos para fazê-lo. Os países africanos tentaram aprovar uma proposta de reparação pelos abusos da escravidão, mas não conseguiram ${ }^{18}$. $\mathrm{O}$ documento final não incluiu um pedido explícito de desculpas por parte de europeus e norte-americanos pela escravidão de negros e índios e pelo colonialismo e muito menos fez referência a alguma forma de reparação. Ciente da obrigação moral dos Estados envolvidos, a declaração exortou os Estados a tomarem medidas apropriadas e efetivas para reverter as consequências dos atos do passado.

A declaração reconheceu que as injustiças históricas contribuíram inegavelmente para a pobreza e o subdesenvolvimento e reconheceu a necessidade de criar programas para o desenvolvimento socioeconômico das sociedades afetadas, em especial nas seguintes áreas: alívio das dívidas externas; erradicação da pobreza; acesso ao mercado; transferência de tecnologia; investimento em saúde e no combate à aids; restituição de objetos de arte e históricos a partir de acordos bilaterais.

Ao reconhecimento da escravidão como crime contra a humanidade (dever de memória), acrescenta-

17 A França foi citada como exemplo por numerosas delegações por ser o único e primeiro país europeu a aprovar, em maio de 2001, um projeto de lei nesse sentido. VUCKOVIC, Nadja. Quem pede reparações, e por quais crimes. In: FERRO, Marc (Org.). O livro negro do colonialismo. Tradução de Joana Angélica D’Ávila Melo. Rio de Janeiro: Ediouro, 2004. p. 884.

18 A respeito das reparações em relação à escravidão na África, Howard-Hassmann e Lombardo elaboraram artigo em que se propuseram a responder por quais motivos os judeus haviam obtido reparações em decorrência do holocausto, mas os africanos ainda não as haviam recebido em relação à escravidão. HOWARD-HASSMANN, Rhoda E.; LOMBARDO, Anthony P. Framing reparations claims: differences between the african and jewish social movements for reparations. African Studies Review, Cambridge, v. 50, n. 1, p. 27-48, Apr. 2007. -se a demanda por desculpas e reparações (dívida moral, jurídica e financeira). Esses passos permitem ao Estado a suspensão de tabus da história, e uma releitura de seu passado, com a abertura de arquivos, processos judiciais, preservação da memória coletiva, e até mesmo a punição de crimes, quando ainda seja possível, ou alguma forma de reparação às vitimas e descendentes, mesmo que por meio de políticas públicas.

Entretanto, verificou-se na Conferência um certo temor de manifestar desculpas e desencadear ações de indenização por perdas e danos de escravos e seus descendentes. A declaração final registrou que a União Europeia apresentou desculpas pelos crimes passados e reconheceu a escravidão e o tráfico negreiro como crimes contra a humanidade. Mas, esclareceu que, em nenhum caso, pagaria indenizações. Foi apoiada, nesse sentido, pelos Estados Unidos da América.

Em relação aos países africanos, dois discursos podem ser identificados: (i) a posição maximalista que demanda o pagamento integral de indenizações sob a forma de transferência de capitais ou anulação da dívida externa dos Estados (anglófonos, como Gana e Nigéria); e (ii) aqueles que demandam o reconhecimento moral e atos de arrependimento (francófonos).

A história do movimento dos direitos humanos, lembra-nos Du Plessis ${ }^{19}$, é a história da estratégia política e do argumento moral em busca da justiça; e o movimento pelos pedidos de reparações segue esse mesmo caminho. O que falta ser trabalhado é a melhor forma de reivindicação das demandas morais pelas reparações. Assim, de modo geral, no âmbito nacional, o tema das desigualdades relacionadas à origem étnica passou a fazer parte das políticas públicas, com o debate a respeito das ações afirmativas. Em tribunais nacionais, principalmente nos Estados Unidos da América, foram empreendidas ações, com o objetivo de obter reparações, por escravos ou descendentes de escravos ${ }^{20}$.

9 PLESSIS, Max Du. Historical injustice and international law: an exploratory discussion of reparation for slavery. Human Rights Quarterly, Maryland, v. 25, n. 3, p. 624-659, Aug. 2003.

20 Contribuiu a obtenção de indenizações pelos judeus, vitimas do holocausto e do trabalho forçado no regime de Hitler junto à Alemanha e Suíça. No mesmo sentido, o ressarcimento dos americanos de origem japonesa aprisionados e internados em campos durante a Segunda Guerra Mundial (obtiveram ganho de causa em 1988, por meio da Civil Liberties Act, após 40 anos de demanda), e as compensações pagas pelo governo americano aos sioux pela espoliação das suas terras. 
Em âmbito nacional, o reflexo do acima comentado ainda é repleto de indagações: qual o discurso internacional do Brasil a este respeito? Qual a posição do Congresso brasileiro quanto a temas relativos aos povos indígenas e aos quilombolas? Como têm sido apreciados pelo Judiciário os casos envolvendo tais temas? Há consideração do Direito Internacional, ao qual o Brasil se obrigou, pelos tribunais? Este artigo não pretende buscar tais respostas, mas sim indicar que a influência do passado colonialista persiste, e suas cicatrizes em termos de impunidade influenciam a posição da sociedade e do Estado para além desses temas. É preciso que os tabus da história brasileira sejam enfrentados.

\section{Os crimes cometidos na repressão militar}

Discutir os crimes contra a humanidade, cometidos na repressão militar, permite retomar temas semelhantes aos comentados - a impunidade, os programas de reparações pecuniárias e simbólicas, as comissões de verdade e reconciliação, as revisões das instituições, o direito à memória, o direito à verdade, o direito ao luto, entre outros tópicos.

Nossa proposição consiste em observar os marcos históricos, que trouxeram à tona o tema do direito à verdade e à justiça no contexto da prática sistemática de violações de direitos humanos ocorridas no período ditatorial. São titulares do direito à verdade e à justiça não só as vítimas e seus familiares, mas também a sociedade. Todos têm o direito a conhecer as formas pelas quais a repressão atuou e os abusos de direitos humanos cometidos. A realização do direito à verdade e à justiça se concretiza, por exemplo, na forma dos relatórios das Comissões de Verdade, em sentenças judiciais nacionais e de organismos internacionais, e em concessão de indenizações no âmbito de programas de reparações.

A título de ilustração, na Argentina, tornaram-se conhecidas as ações no sentido de se buscar o direito à verdade, ou seja, o direito dos familiares de conhecerem o destino final de seus entes e o direito da sociedade de conhecer com detalhes a metodologia utilizada pela ditadura militar para exterminar os argentinos. Essas foram necessidades que levaram as pessoas aos tribunais alegando o "direito de saber a verdade" 21 . O Centro de Estudios

ABREGÚ, Martín. La tutela judicial del derecho a la verdad en la Argentina. Revista do Instituto Interamericano de Direitos do Homem, San José, v. 24, p. 11- 47, 1996.
Legales y Sociales (CELS) iniciou uma série de causas judiciais destinadas a obter a continuação das investigações, mesmo após as leis de anistias, com base no direito à verdade ${ }^{22}$. Essas ações fundavam-se, explicitamente, no direito subjetivo dos familiares e do povo de conhecerem a sua história, isto é, um direito de saber e conhecer o que se passou com cada uma das pessoas desaparecidas e de obter toda a informação referida à organização do terror de Estado, que fez com que muitos, que tiveram chance, abandonassem seu país em busca de proteção.

Uma questão central da tramitação desses processos era a determinação do alcance da reativação da investigação que se solicitava. Nesse sentido, na época em que foram sendo propostas essas ações, muitos sustentavam que não se devia reavivar as investigações porque a aplicação das leis do Ponto Final e da Obediência Devida impediam a continuidade dos processos. Sem ignorar a existência dessa legislação que inibia a realização da justiça como tal, o pedido dos familiares era de conteúdo distinto: não se solicitava a retomada dos procedimentos com o objetivo de sancionar os culpados, mas, sim, de determinar os fatos que rodeavam o cometimento dos delitos.

Posteriormente, na Argentina, em 2003, o governo revogou as leis que liberavam os agentes da repressão de responsabilidades passadas. E, de modo mais específico, em 2005, uma decisão da Corte Suprema de Justiça da Argentina considerou que as leis de ponto final (Lei 23.492/86) e de obediência devida (Lei 23.521/87), as quais impediam o julgamento de violações cometidas no regime repressivo de 1976 a 1983, eram incompatíveis com a Convenção Americana de Direitos Humanos; o que permitiu o julgamento de militares por crimes praticados durante a repressão. Dessa forma, as principais causas sobre crimes contra a humanidade foram reabertas pela Justiça.

No Uruguai, é possível verificar que o tema foi retomado, no final de abril de 1995, quando o capitão

Nessa linha de trabalho, o primeiro caso escolhido foi o de Mônica Candelaria Mignone, filha de Emilio F. Mignone, presidente da CELS. Mônica Candelaria trabalhava como catequista em Villa del Bajo Flores e foi sequestrada em seu domicílio em 14 de maio de 1976. E o segundo caso foi de Alejandra Lapacó, filha de Carmen Aguiar de Lapacó, mãe da Plaza de Mayo e membro da comissão diretiva da CELS. Alejandra Lapacó, estudante de antropologia, foi seqüestrada juntamente com sua mãe em 17 de março de 1977, sendo que sua mãe (Carmen Lapacó) foi liberada no dia 19 de março do mesmo ano. 
da marinha Adolfo Scilingo confessou publicamente sua participação nos voos que levavam vítimas da repressão militar para o oceano, onde elas eram atiradas do avião depois de terem sido fortemente sedadas. Em maio de 1996, o também capitão da marinha Jorge Troccoli relatou a forma como se torturavam e matavam os inimigos do regime ditatorial. Posteriormente, em 16 de novembro de 2006, o ex-ditador uruguaio Juan María Bordaberry e o ex-Ministro de Relações Exteriores, Juan Carlos Blanco, foram condenados e presos por terem ordenado o sequestro e o assassinato dos congressistas Zelmar Michelini e Héctor Gutiérrez Ruiz. E, em 20 de dezembro de 2006, o ex-ditador foi novamente condenado pelo desaparecimento forçado de outras dez pessoas.

Da mesma forma, o assunto ressurgiu no Chile, na década de 1990, por meio de um caso que permaneceu formalmente excluído do rol dos benefícios da anistia: tratava-se do caso Letelier. Em 31 de setembro de 1976, Orlando Letelier del Solar, ex-embaixador do Chile para os Estados Unidos, e sua secretária morreram em consequência da explosão de um carro em Washington. Quase duas décadas depois, em 30 de maio de 1995, a Suprema Corte Chilena manteve a sentença do juízo de primeira instância considerando o General Manuel Contreras e o Brigadeiro Pedro Espinoza como os autores intelectuais daquele crime. Posteriormente, houve o processo do General Augusto Pinochet Ugarte como autor de graves violações dos direitos humanos, o qual se encerrou, sem a obtenção de uma sentença, devido ao falecimento do acusado, em 10 de dezembro de 2006.

No Peru, por força das sentenças da Corte Interamericana de Direitos Humanos ${ }^{23}$, leis de anistia também foram invalidadas, com fundamento no dever do Estado de investigar, processar, punir e reparar graves violações de direitos humanos. Em 4 de junho de 2001, foi criada a Comissão da Verdade e Reconciliação, por meio do Decreto Supremo 065-2001-PCM do governo provisório, denominando-se Comissão da Verdade e Reconciliação

23 CORTE INTERAMERICANA DE DIREITOS HUMANOS. Caso Barrios Altos versus Peru. Julgamento de 14 de março de 2001. Disponível em: <http://www.corteidh. or.cr/docs/casos/articulos/Seriec_75_esp.pdf >. Acesso em: 23 mar. 2016. $\$$ 41. CORTE INTERAMERICANA DE DIREITOS HUMANOS. Caso La Cantuta versus Peru. Julgamento de 29 de novembro de 2006. Disponível em: <http:// www.corteidh.or.cr/docs/casos/articulos/seriec_162_esp. pdf $>$. Acesso em: 23 mar. 2016.
(Decreto Supremo 101-2001-PCM), incluindo atos dos agentes de Estado e das organizações terroristas.

No Brasil, a partir de 2010, o tema a respeito das violações de direitos humanos cometidas durante o período militar foi revigorado por meio dos resultados de duas demandas, propostas em distintas esferas judiciais, e que tomaram rumos opostos. São elas: o caso Gomes Lund e outros contra o Brasil (Caso Guerrilha do Araguaia), que tramitou na Corte Interamericana de Direitos Humanos (CIDH); e a Arguição de Descumprimento de Preceito Fundamental (ADPF) 153, proposta pelo Conselho Federal da Ordem dos Advogados do Brasil (OAB), perante o Supremo Tribunal Federal (STF). Junta-se também a esses marcos históricos a entrega do Relatório Final da Comissão Nacional de Verdade (CNV), ocorrido em dezembro de 2014.

Com os esforços da atuação do $\mathrm{MPF}^{24}$ - que vem instaurando procedimentos de investigação criminal e ajuizando ações penais contra agentes civis e militares ligados aos crimes cometidos na ditadura seguindo, assim, as recomendações do próprio Relatório da CNV e da sentença da CIDH no Caso Araguaia - o Brasil luta hoje para deixar de ser o país mais atrasado do continente no debate dos abusos praticados em períodos militares, tanto no que se refere à busca pela verdade quanto pela justiça.

Consoante as conclusões da CNV, foram confirmadas 434 mortes e desaparecimentos de vítimas do regime militar, sendo 191 os mortos, 210 os desaparecidos e 33 os desaparecidos cujos corpos tiveram seu paradeiro posteriormente localizado ${ }^{25}$. A própria CNV alertou para o fato de que esses números, certamente, não correspondem ao total de mortos edesaparecidos, mas apenas ao de casos cuja comprovação foi possível em função do trabalho realizado, tendo em vista as dificuldades encontradas na investigação, em especial, a falta de acesso aos documentos produzidos pelas Forças Armadas, oficialmente dados como destruídos.

Certamente, existem outros marcos históricos

24 BRASIL. Ministério Público Federal. Grupo de Trabalho Justiça de transição: atividades de persecução penal desenvolvida pelo Ministério Público Federal, 2011/2013. Brasília, 2014. Disponível em: <http://2ccr.pgr.mpf.mp.br/ coordenacao/grupos-de-trabalho/justica-de-transicao/ relatorios-1/Relatorio\%20Justica\%20de\%20Transicao\%20 -\%20Novo.pdf >. Acesso em: 06 jul. 2015.

25 BRASIL. Comissão Nacional da Verdade. Relatório da Comissão Nacional da Verdade. Brasília: CNV, 2014. v. 1. Disponível em: < http://www.cnv.gov.br/images/pdf/relatorio/ volume_1_digital.pdf $>$. Acesso em: 10 jul. 2015. p. 963. 
que, no cenário brasileiro, auxiliaram numa evolução paulatina a fim de que fosse alcançada a elaboração do Relatório Final da CNV, afinal, passaram-se 30 anos desde o início da redemocratização no país.

O início do reconhecimento de responsabilidade do Estado Brasileiro pelas violações de direitos humanos praticadas na ditadura militar se deu com a Lei 9.140/1995, conhecida como Lei dos Mortos e Desaparecidos Políticos que, em seu anexo I, disponibilizou os nomes e dados de 136 desaparecidos. Além disso, a mesma Lei instituiu a Comissão Especial sobre Mortos e Desaparecidos Políticos (CEMDP).

Posteriormente, a Lei 10.559/2002 regulamentou a condição de "anistiado político", nos termos do artigo $8^{\circ}$ do Ato das Disposições Constitucionais Transitórias (ADCT), que previa a concessão de anistia aos que houvessem sido atingidos por motivações exclusivamente políticas; e reconheceu a Comissão de Anistia, vinculada ao Ministério da Justiça, como o órgão responsável por reparar os atos de exceção cometidos entre 1946 e 1988, e para tanto, apta a realizar diligências, requerer informações e documentos, ouvir testemunhas, emitir pareceres técnicos e arbitrar indenizações. A Comissão de Anistia organizou, também, as "caravanas de anistia", com o intuito de divulgar a questão das violações de direitos humanos cometidas na ditadura.

Outro antecedente foi a publicação do Relatório "Direito à Memória e à Verdade", em 2007, pela Secretaria Nacional de Direitos Humanos. E, cabe lembrar, também, que, em dezembro de 2009, por ocasião da XI Conferência Nacional de Direitos Humanos, cujo objetivo era revisar o Programa Nacional de Direitos Humanos (PNDH), houve a recomendação para a criação da CNV. Com a aprovação do $3^{\circ}$ Programa Nacional dos Direitos Humanos (PNDH-3), por meio do eixo orientador " $\mathrm{Di}$ reito à memória e à verdade", o tema recebeu destaque e, ao mesmo tempo, foi alvo de severas críticas e posições contrárias, visto que as duas primeiras edições do PNDH faziam citações apenas indiretas a esses direitos, quando mencionavam reparações para as graves violações de direitos humanos.

Em continuidade a $\mathrm{PNDH}-3$, por ato presidencial, em de 13 de janeiro de 2010, foi instituído um grupo de trabalho com o objetivo de elaborar o anteprojeto de lei para a criação da CNV. O projeto de lei foi concluído em maio de 2010 e a Lei 12.528/2011 foi sancionada em 18 de novembro de 2011. O Relatório Final, resultante dos trabalhos da CNV, foi entregue em 10 de dezembro de 2014.

Em suas conclusões, a CNV foi enfática ao afirmar que havia sido caracterizada a prática de crimes contra a humanidade durante a ditadura brasileira:

Ao demonstrar por meio da apuração registrada neste Relatório que as graves violações de direitos humanos praticadas pelo regime militar ocorreram em um contexto generalizado e sistemático de ataque do Estado contra a população civil - foram atingidos homens, mulheres, crianças, adolescentes e idosos, vinculados aos mais diferentes grupos sociais, como trabalhadores urbanos, camponeses, estudantes, clérigos, dentre tantos outros -, a CNV constatou que a prática de detenções ilegais e arbitrárias, tortura, execuções, desaparecimentos forçados e ocultação de cadáveres por agentes do Estado durante a ditadura militar caracterizou o cometimento de crimes contra a humanidade ${ }^{26}$.

Com a propositura da ADPF 153, foram reabertos os debates a respeito do alcance da Lei de Anistia. Nesse sentido, diferentes argumentos surgiram, os quais podem ser agrupados como segue: (i) favoráveis à revisão da Lei de Anistia para salvaguarda da justiça e da verdade; e (ii) favoráveis a colocar uma pedra em cima do assunto para salvaguardar a conciliação nacional. Em linhas gerais, os que defendem a anistia equiparam os crimes cometidos pela repressão aos crimes cometidos pelos grupos armados de esquerda e, buscam o não enquadramento das violações cometidas como sendo crimes contra a humanidade. Esta última perspectiva é conhecida como teoria dos "dois demônios", que coloca todos na mesma categoria, desconsiderando que os crimes cometidos pela repressão, apoderaram-se dos meios públicos, utilizaram a máquina estatal para torturar e executar opositores, constituindo crimes contra a humanidade que não são passíveis de anistia, prescrição ou qualquer outra forma de esquecimento.

A ADPF 153, proposta pelo Conselho Federal da Ordem dos Advogados do Brasil (OAB), em 21 de outubro de 2008, reavivou essa discussão, pois questionava a interpretação do $\$ 1^{\circ}$ do artigo $1^{\circ}$ da Lei 6.683/1979 (Lei de Anistia). Em sua petição inicial, a OAB pedia para que o STF fizesse uma interpretação conforme a Constituição Federal de 1988, de modo a declarar, a luz dos seus preceitos fundamentais, que a anistia concedida aos crimes

26 BRASIL. Comissão Nacional da Verdade. Relatório da Comissão Nacional da Verdade. Brasília: CNV, 2014. v. 1. Disponível em: < http://www.cnv.gov.br/images/pdf/relatorio/ volume_1_digital.pdf $>$. Acesso em: 10 jul. 2015. p. 964. 
políticos ou conexos não se estenderia aos crimes comuns praticados pelos agentes da repressão contra opositores políticos durante o regime militar.

O Ministro Relator da ADPF 153, Eros Grau, afirmou que existiria uma conformidade entre a Lei de Anistia e a ordem constitucional de 1988, e votou, assim, pela improcedência do pedido. No julgamento de abril de 2010, a ADPF 153 foi rejeitada por maioria de sete votos, que acompanharam o relator, contra dois.

As discussões que foram levantadas na ADPF 153 eram as mesmas que, em 1979, foram apontadas por ocasião das propostas de emenda ao projeto de Lei de Anistia. Ou seja, a imagem que se fixou em meio à sociedade foi de que, a partir da anistia, com o retorno dos exilados políticos, a reconciliação e a pacificação dos espíritos seriam realmente possíveis e que, utilizando-se do argumento do mal menor ${ }^{27}$, ainda que também se concedesse anistia aos agentes estatais, este mal seria justificável em nome da transição política. Essa anistia, que liberava e concedia o esquecimento tanto dos crimes políticos, praticados pelos cidadãos contra o Estado, quanto das violações dos direitos humanos, perpetradas pelo Estado contra seus cidadãos, foi reconhecida, no Brasil, como de "mão dupla" ou de "dupla via".

É preciso observar, no entanto, se o fundamento da anistia de dupla via repousa realmente em justificativas teóricas sobre crimes políticos e violações dos direitos humanos. Inicialmente, deve-se reforçar a distinção entre: (i) leis de anistia oferecidas pelos Estados aos seus opositores, normalmente por crimes políticos, e (ii)

27 Sobre o argumento do "mal menor", a proposição de que a adoção de uma lei de anistia, que dispensa a responsabilização pelos crimes cometidos no passado, mostra-se mais conveniente do que se suportar um período de conflito e de transição violenta em muito se assemelha à chamada teoria do mal menor, pois, de acordo com essa justificação moral, quando se está diante de dois males, há que se optar sempre pelo menor. Se aplicada para o tema das anistias, a teoria do mal menor tenderia a explicar que, diante (i) do esquecimento dos crimes que foram cometidos e (ii) de uma transição política violenta, o melhor seria a opção pela anistia, um mal menor. Porém, a utilização desse argumento é questionável. Hannah Arendt lembra que a sua fraqueza está em que, ainda que se tenha escolhido o mal menor, este continua a ser um mal. E, com o passar dos anos, a tendência é que isso seja raramente lembrado pela população. O perigo se encontra justamente no risco de se esquecer que se praticou um mal ainda que em pequena dimensão. ARENDT, Hannah. Responsabilidade e julgamento. São Paulo: Companhia das Letras, 2004. p. 99. aquelas que concedem imunidade ao próprio Estado pelos atos cometidos por seus agentes.

$\mathrm{O}$ entendimento defendido pelo Direito Internacional é de que apenas o primeiro caso encontra-se no rol dos direitos do Estado, devido ao seu papel de vítima da agressão e de garantidor das leis penais estatais, e esse direito não deveria se estender a situações nas quais o próprio Estado, por meio dos seus agentes, é o perpetrador das violações ${ }^{28}$.

$\mathrm{Na}$ experiência brasileira, haveria que se romper com a insustentável interpretação de que, em nome da conciliação nacional, a Lei de Anistia seria uma lei de duas mãos, a beneficiar torturadores e vítimas. Esse entendimento advém da equivocada leitura da expressão crimes conexos constante da lei, cuja oportunidade de revisão foi reaberta por ocasião da ADPF 153, mas que não logrou êxito.

Acerca da diminuta aplicação do Direito Internacional e do não reconhecimento, pelo STF, a respeito das obrigações internacionais que o Brasil assumiu, o julgamento da ADPF 153 evidencia o problema central do DIDH: as fissuras existentes na concepção teórica da interação entre as normas de Direito Internacional e de Direito Interno, ou seja, o resgate da antiga distinção entre as teorias monista ou dualista ${ }^{29}$. Em seu voto, o Ministro Relator da ADPF $153^{30}$ se desdobrou em fazer diferenciações acerca da Lei de Anistia:

O debate a esse respeito seria, todavia, despiciendo. A uma por que, como vimos, foi mera lei-medida, dotada de efeitos concretos, exauridos --- repito, parenteticamente, o que observei linhas acima: a lei-medida consubstancia um comando concreto revestindo a forma de nor-

28 GOLDMAN, Robert. Amnesty laws and international law: a specific case. In: SEMINAR ON JUSTICE NOT IMPUNITY, data, local. Annals... Geneva: ICJ, 1992.

29 A questão teórica é, normalmente, definida como um embate entre dualismo e monismo. Essas duas escolas de pensamento apresentam a hipótese de que existe um espaço comum no qual as ordens jurídicas internacional e interna podem atuar de maneira simultânea em relação a um mesmo fato. O problema que então se coloca é o de saber qual é a ordem jurídica que deve prevalecer e ser aplicada. BROWNLIE, Ian. Princípios de direito internacional público. Lisboa: Fundação Calouste Gulbenkian, 1997. p. 44.

30 BRASIL. Supremo Tribunal Federal. Arguição de Descumprimento de Preceito Fundamental. ADPF 153 DF. Tribunal Pleno. Arguente: Conselho Federal da Ordem dos Advogados. Arguido: Associação Juízes para a Democracia. Relator: Min. Eros Grau. Brasília, 29 de abril de 2010. Disponível em: <http://redir.stf.jus.br/paginadorpub/paginador.jsp? docTP $=\mathrm{AC} \& \mathrm{docID}=612960>$. Acesso em: 15 ago. 2015. 
ma geral, mas traz em si mesma o resultado específico pretendido, ao qual se dirige; é lei apenas em sentido formal, não o sendo, contudo, em sentido material; é lei não-norma.

Entretanto, face a esse rigor formal, a fim de que se alcance a verdadeira eficácia dos direitos humanos, nas palavras de Cançado Trindade ${ }^{31}$, seria:

[...] tempo de superar certos ranços do passado, de afastar de vez o hermetismo de certas construções artificiais fictícias. O formalismo do requisito do conhecimento da norma jurídica, por exemplo, tem sido, por vezes, levado a extremos inaceitáveis, em detrimento dos direitos individuais [...]. Não há como reconhecer ou admitir as obrigações convencionais contraídas por um Estado no plano internacional e ao mesmo tempo negar-lhes vigência no plano do direito interno.

Comparando-se o julgamento do STF face à sentença da CIDH, no Caso Araguaia, no julgamento da ADPF 153 não há referência expressa ao caso, apesar de que o Brasil já tivesse sido clamado a adotar as medidas necessárias para que Lei de Anistia não continuasse representando um obstáculo para a persecução penal de graves violações de direitos humanos que constituíssem crimes contra a humanidade. Já a CIDH, por ocasião de sua sentença, fez menção expressa à $\mathrm{ADPF} 153^{32}$.

Surpreendentemente, os tratados internacionais do sistema interamericano de direitos humanos e a jurisprudência da $\mathrm{CIDH}$ não foram utilizados no julgamento da ADPF 153. O Brasil, ao recusar a jurisprudência da $\mathrm{CIDH}$, perdeu a oportunidade de aplicar aquilo que tem sido considerado como muito rico, original e, sob certos aspectos, audacioso ${ }^{33}$.

A CIDH já apreciou diversas anistias concedidas

31 TRINDADE, Antônio Augusto Cançado. Tratado de direito internacional dos direitos humanos. Porto Alegre: S. A. Fabris, 1997. p. 437.

32 Nos dizeres da Corte: "Em 29 de abril de 2010, o Supremo Tribunal Federal, por sete votos a dois, declarou a improcedência da Arguição de Descumprimento de Preceito Fundamental, interposta pela Ordem dos Advogados do Brasil, e afirmou a vigência da Lei de Anistia e a constitucionalidade da interpretação do $\$ 1^{\circ}$ do seu artigo $1^{\circ}$ (supra pars. 44 e 58)". Ver: $₫ 136$. CORTE INTERAMERICANA DE DIREITOS HUMANOS. Caso Gomes Lund e outros ("Guerrilha Do Araguaia") vs. Brasil. Julgamento de 24 de novembro de 2010. Disponível em: <http://www.corteidh. or.cr/docs/casos/articulos/seriec_219_por.pdf $>$. Acesso em: 15 ago. 2015.

33 MARTIN-CHENUT, Kathia. Introduction. In: MARTIN-CHENUT, Kathia; ABDELGAWAD, Elisabeth Lambert. Réparer les violations graves et massives des droits de l'homme: la Cour Interaméricaine, pionnière et modèle? Paris: Société de Legislation Compare, 2010, p. 26. em situações semelhantes à anistia brasileira e todas foram julgadas como sendo inválidas e inaplicáveis, condenando-se os Estados que as tinham emitido ${ }^{34}$. A grande maioria dos pedidos oferecidos diante desse Tribunal se fundamenta nos direitos elencados na Convenção Americana de Direitos Humanos, incluindo o direito à justiça e o direito à proteção judicial. Atualmente, esses casos fornecem a única análise sistemática e significativa do tema verificado por um tribunal internacional. E a jurisprudência da CIDH foi fixada no sentido de que a anistia aos agentes que praticam crimes contra a humanidade é uma violação fundamental ao Direito Internacional.

No Caso Araguaia ${ }^{35}$, a CIDH foi bastante clara ao enfatizar que, desde sua primeira sentença, sempre destacou a importância do dever estatal de investigar e punir as violações de direitos humanos. A obrigação de investigar e, se for o caso, julgar e punir, adquire particular importância ante a gravidade dos crimes cometidos e a natureza dos direitos ofendidos, especialmente em vista de que a proibição do desaparecimento forçado de pessoas e o correspondente dever de investigar e punir os responsáveis há muito alcançaram o caráter de jus cogens.

Em seu julgamento, a $\mathrm{CIDH}^{36}$ decidiu que a aplicação de leis de anistia a perpetradores de graves violações de direitos humanos é contrária às obrigações estabelecidas na Convenção e à sua própria jurisprudência. Em casos de execução e desaparecimento forçado, os artigos $8^{\circ}$ e 25 da Convenção Americana de

34 Ver a afirmação da Corte, no Caso Araguaia, em seu $\$ 149$ : "No Sistema Interamericano de Direitos Humanos, do qual Brasil faz parte por decisão soberana, são reiterados os pronunciamentos sobre a incompatibilidade das leis de anistia com as obrigações convencionais dos Estados, quando se trata de graves violações dos direitos humanos. Além das mencionadas decisões deste Tribunal, a Comissão Interamericana concluiu, no presente caso e em outros relativos à Argentina, Chile, El Salvador, Haiti, Peru e Uruguai, sua contrariedade com o Direito Internacional". CORTE INTERAMERICANA DE DIREITOS HUMANOS. Caso Gomes Lund e outros ("Guerrilha Do Araguaia") vs. Brasil. Julgamento de 24 de novembro de 2010. Disponível em: <http:// www.corteidh.or.cr/docs/casos/articulos/seriec_219_por. pdf>. Acesso em: 15 ago. 2015.

$35 \$ 137$. CORTE INTERAMERICANA DE DIREITOS HUMANOS. Caso Gomes Lund e outros ("Guerrilha Do Araguaia”) vs. Brasil. Julgamento de 24 de novembro de 2010. Disponível em: <http://www.corteidh.or.cr/docs/casos/articulos/seriec_219_por.pdf $>$. Acesso em: 15 ago. 2015.

$36 \$ 127$. CORTE INTERAMERICANA DE DIREITOS HUMANOS. Caso Gomes Lund e outros ("Guerrilha Do Araguaia") vs. Brasil. Julgamento de 24 de novembro de 2010. Disponível em: <http:/www.corteidh.or.cr/docs/casos/articulos/seriec_219_por.pdf>. Acesso em: 15 ago. 2015. 
Direitos Humanos estabelecem que os familiares das vítimas têm o direito a que a morte ou o desaparecimento sejam efetivamente investigados pelas autoridades estatais, que os responsáveis sejam processados e, se for o caso, punidos, e que se reparem os danos que os familiares tenham sofrido. Do mesmo modo, nenhuma lei ou norma de direito interno, como as disposições de anistia, as regras de prescrição e outras excludentes de responsabilidade, pode impedir que um Estado cumpra essa obrigação, especialmente quando se trate de graves violações de direitos humanos que constituam crimes contra a humanidade, como os desaparecimentos forçados, pois esses crimes são inanistiáveis e imprescritíveis.

A CIDH também se atentou para o fato de que meras formalidades burocráticas não são suficientes para garantir o direito à verdade ${ }^{37}$ :

O Tribunal reitera que a obrigação de investigar violações de direitos humanos encontra-se dentro das medidas positivas que os Estados devem adotar para garantir os direitos reconhecidos na Convenção. O dever de investigar é uma obrigação de meios e não de resultado, que deve ser assumida pelo Estado como um dever jurídico próprio e não como uma simples formalidade, condenada de antemão a ser infrutífera, ou como mera gestão de interesses particulares, que dependa da iniciativa processual das vítimas, de seus familiares ou da contribuição privada de elementos probatórios. À luz desse dever, uma vez que as autoridades estatais tenham conhecimento do fato, devem iniciar, ex officio e sem demora, uma investigação séria, imparcial e efetiva. Essa investigação deve ser realizada por todos os meios legais disponíveis e deve estar orientada à determinação da verdade.

Por fim, não apenas a Organização dos Estados Americanos (OEA), por meio da atuação de seus órgãos: Comissão Interamericana de Direitos Humanos e Corte Interamericana de Direitos Humanos, tem dedicado atenção especial ao tema das anistias, a ONU, por intermédio da Assembleia Geral ${ }^{38}$, do Conselho Econômico e

$\$ 138$. CORTE INTERAMERICANA DE DIREITOS HUMANOS. Caso Gomes Lund e outros ("Guerrilha Do Araguaia") vs. Brasil. Julgamento de 24 de novembro de 2010. Disponível em: $<$ http://www.corteidh.or.cr/docs/casos/articulos/seriec_219 por.pdf >. Acesso em: 15 ago. 2015.

38 Declaration on the Protection of all Persons from Enforced Disappearance, General Assembly Res. 47/133, 47th Session, de 1992, art. 18, afirmando que a anistia não deve ser concedida para beneficiar aqueles que são responsáveis pelos crimes de desaparecimento. General Assembly Res. 2840, 26th Session, de 1971. General Assembly Res. 2712,
Social ${ }^{39}$ (CES) e da antiga Comissão de Direitos Huma$\operatorname{nos}^{40}$, já se manifestou contrariamente à anistia aplicada para violações dos direitos humanos, fundamentando que esta viola o Direito Internacional.

As leis de anistia vão contra as normas internacionais de direitos humanos e as obrigações assumidas pelos Estados no plano internacional pela ratificação de tratados e pelo Direito Internacional costumeiro. A opção da anistia em prol da reconciliação nacional deve ser valorada.

\section{Conclusão}

Marc Ferro observa que o estudo do colonialismo pode tomar de empréstimo seus instrumentos ou observações à análise de outras experiências históricas, tais como os regimes totalitários. ${ }^{41}$ É nesse espírito, que esse ensaio buscou analisar os crimes contra a humanidade, perpetrados no Brasil, que compartilham demandas se-

25th Session, de 1970, art. 5. General Assembly Res. 2583, 24th Session de 1969, art. 8.

39 Economic and Social Council Resolution 1989/65, de 24 May 1989, denominada Principles on the Effective Prevention and Investigation of Extra-legal, Arbitrary and Summary Executions: (1) Governments shall prohibit by law all extra-legal, arbitrary and summary executions and shall ensure that any such executions are recognized as offences under their criminal laws, and are punishable by appropriate penalties which take into account the seriousness of such offences. Exceptional circumstances including a state of war or threat of war, internal political instability or any other public emergency may not be invoked as a justification of such executions. [...] (19) In no circumstances, including a state of war, siege, or other public emergency, shall blanket immunity from prosecution be granted to any person allegedly involved in extra-legal, arbitrary or summary executions.

40 Report of the Human Rights Committee, U.N. Doc. A/47/40 (1992), Anexo VI, \$15, p. 191, afirmando que anistias para tortura são geralmente incompatíveis com as obrigações dos Estados diante do direito internacional: 15. El Comité ha observado que algunos Estados han concedido amnistía respecto de actos de tortura. Las amnistías son generalmente incompatibles con la obligación de los Estados de investigar tales actos, de garantizar que no se cometan tales actos dentro de su jurisdicción y de velar por que no se realicen tales actos en el futuro. Los Estados no pueden privar a los particulares del derecho a una reparación efectiva, incluida la indemnización y la rehabilitación más completa posible. Available at: <http://www.unhchr.ch/tbs/doc.nsf/898586b1dc7b4043c1256a450044f331/7067af17320f5 f6ec12569e4004e73bc/\$FILE/N9314650.pdf>. Access: Aug. 15, 2015.

${ }^{41}$ FERRO, Marc. O livro negro do colonialismo. Tradução de Joana Angélica D’Ávila Melo. Rio de Janeiro: Ediouro, 2004. p. 11. 
melhantes face à impunidade que os caracteriza, mesmo tendo sido perpetrados em condições e tempos diferentes.

Todavia, como observa Georges Balandier:

Cada sociedade, a seu modo, define as verdades que tolera, os limites que ela impõe ao que não está em sua estrita conformidade, o espaço que ela concede à liberdade modificadora e à mudança. Ela não cessa jamais de restabelecer demarcações, de reavivar os interditos, de reproduzir os códigos e as convenções. ${ }^{42}$

Ao longo da história, o Brasil adotou a Constituição Federal de 1988, emendada pela Emenda Constitucional 45/2004, conhecida pelas mudanças na questão de direitos humanos, incluindo o deslocamento de competência e o processo de aprovação dos tratados de direitos humanos, e o país se tornou Estado-Membro do TPI.

Entretanto, não há como se negar que as posturas da sociedade e do Estado Brasileiro, hoje, repercutem os resultados do tratamento dado tanto aos crimes históricos quanto àqueles cometidos no regime ditatorial. Paulo Sérgio Pinheiro ${ }^{43}$ já apontava que, apesar de a Constituição de 1988 ter sido promulgada como sendo a carta mais completa e abrangente em toda a história política do país no que se refere aos direitos e garantias fundamentais, subsiste uma violência sistêmica, em que o Estado de Direito, se combina com altos índices de criminalidade violenta, crime organizado, grande intensidade de violência física nos conflitos entre os cidadãos e impunidade generalizada. Essa violência de caráter endêmico, implantada no sistema de relações sociais profundamente assimétricas, não é um fenômeno novo no Brasil: é a continuação de longa tradição de práticas de autoritarismo.

Cabe lembrar, tal como ponderado por Cassesse ${ }^{44}$, que a racionalidade existente por trás do esquecimento é questionável. É duvidoso que, ao final de um conflito armado, de uma guerra civil ou de uma revolução, o melhor para curar as feridas sociais seja esquecer o passado e liberar a responsabilidade pelos crimes cometidos. As marcas morais e psicológicas decorrentes da comissão de graves violações envolvendo grupos étnicos, religiosos ou políticos, não podem ser apagadas.

42 BALANDIER, Georges. O poder em cena. Brasília: UnB, 1982.

43 PINHEIRO, Paulo Sérgio. O passado não está morto: nem passado é ainda. In: DIMENSTEIN, Gilberto. Democracia em pedaço: direitos humanos no Brasil. São Paulo: Companhia das Letras, 1996.

44 CASSESE, Antônio. International criminal law. New York: Oxford University, 2003. p. 312-313.
O Relatório Joinet ${ }^{45}$ sobre a questão da impunidade dos perpetradores das violações dos direitos humanos propôs, a respeito do princípio do direito à justiça, que não pode existir reconciliação que perdure sem uma resposta efetiva à necessidade de justiça, e o requisito prévio para qualquer reconciliação seria o perdã $0^{46}$.

A sociedade tem o direito de conhecer sua história, resgatar o que ocorreu nos anos passados e abrir os arquivos secretos. $\mathrm{O}$ direito à verdade assegura o direito à construção da identidade, da história e da memória coletiva. Serve a um duplo propósito: proteger o direito à memória das vítimas e confiar às gerações futuras a responsabilidade de prevenir a repetição de tais práticas. Sob a ótica republicana e democrática, rompe-se com o pacto do silêncio e com uma injustiça continuada. Lançam-se luzes à dimensão sombria de nossa história, na defesa dos direitos à justiça, à verdade e à memória individual e coletiva. Permitindo-se ainda com esse conhecimento, realizar o direito à justiça, em suas diversas formas, como o julgamento ou políticas públicas.

A oportuna discussão sobre os crimes contra a humanidade cometidos no Brasil encontra seu fundamento, portanto, na premissa de que a sua finalidade não é a "criminalização da história", mas sim a "civilização do mundo", dentro do duplo censo de fazer cessar as violações aos direitos humanos e de promover o Direito ${ }^{47}$, relembran-

Relatório Final, Resolução 1996/119, E.CN.4/ Sub.2/1997/20, de 26 de junho de 1997. UNITED NATIONS. Question of the impunity of perpetrators of human rights violations (civil and political): final report prepared by Mr. Joinet pursuant to Sub-Commission decision 1996/119. June 1997. Available at: <http://www.refworld. org/docid/3b00f1a124.html>. Access: Mar. 22, 2016.

46 Sobre o direito à justiça, a função do perdão e a importância das comissões de verdade e reconciliação, Cláudia Perrone-Moisés já se pronunciou no sentido de que: “Talvez estejamos vivendo uma época em que é possível encontrar um lugar entre o perdão e a punição. As Comissões de Verdade e Reconciliação podem ser entendidas como espaços onde as vítimas, seus familiares e a sociedade têm a possibilidade de se reconciliar com o passado, compreendendo o que se passou, fazendo com que o indivíduo se sinta de novo em casa no mundo, como diria Hannah Arendt. Talvez Derrida tenha razão ao dizer que o perdão é algo ligado ao divino, pois é difícil pensar em perdoar os crimes contra a humanidade se nos situarmos apenas nos "assuntos humanos”. PERRONE-MOISÉS, Cláudia. O perdão e os crimes contra a humanidade: um diálogo entre Hannah Arendt e Jacques Derrida. In: CORREIA, Adriano (Org.). Hannah Arendt e a condição humana. Salvador: Quarteto, 2006. p. 222.

47 GARAPON, Antoine. Peut-on réparer l'histoire? colonisation, esclavage, shoah. Paris: O. Jacob, 2008. p. 21-22. 
do que o Brasil atualmente encontra-se obrigado perante um conjunto de normas internacionais que engrandeceu o arcabouço jurídico de proteção do ser humano, que não mais pode ser desconsiderado em atenção ao Estado democrático de direito em que vivemos.

\section{Referências}

O ESCRAVO Macota. O Estado de São Paulo, São Paulo, p. 3-4, 16 nov. 1876.

ABREGÚ, Martín. La tutela judicial del derecho a la verdad en la Argentina. Revista do Instituto Interamericano de Direitos do Homem, San José, v. 24, p. 11-47, 1996.

ARENDT, Hannah. Origens do totalitarismo. São Paulo: Companhia das Letras, 1989.

ARENDT, Hannah. Responsabilidade e julgamento. São Paulo: Companhia das Letras, 2004.

BALANDIER, Georges. O poder em cena. Brasília: UnB, 1982.

BRASIL. Comissão Nacional da Verdade. Relatório da Comissão Nacional da Verdade. Brasília: CNV, 2014. v. 1. Disponível em: < http://www.cnv.gov.br/images/pdf/ relatorio/volume_1_digital.pdf>. Acesso em: 10 jul. 2015.

BRASIL. Ministério Público Federal. Grupo de Trabalho Justiça de transição: atividades de persecução penal desenvolvida pelo Ministério Público Federal, 2011/2013. Brasília, 2014. Disponível em: <http://2ccr.pgr.mpf. $\mathrm{mp}$.br/coordenacao/grupos-de-trabalho/justica-de-transicao/relatorios-1/Relatorio\%20Justica\%20de\%20Transicao\%20-\%20Novo.pdf>. Acesso em: 06 jul. 2015.

BRASIL. Ministério Público Federal. Relatório Figueiredo. Disponivel em: <http://6ccr.pgr.mpf.mp.br/institucional/ grupos-de-trabalho/gt_crimes_ditadura/relatorio-figueiredo $>$. Acesso em: 28 ago. 2015.

BRASIL. Supremo Tribunal Federal. Arguição de Descumprimento de Preceito Fundamental. ADPF 153 DF. Tribunal Pleno. Arguente: Conselho Federal da Ordem dos Advogados. Arguido: Associação Juízes para a Democracia. Relator: Min. Eros Grau. Brasília, 29 de abril de 2010. Disponível em: $<$ http://redir.stf.jus.br/paginadorpub/paginador.jsp?doc$\mathrm{TP}=\mathrm{AC} \&$ docID=612960 > . Acesso em: 15 ago. 2015.

BROWNLIE, Ian. Princípios de direito internacional público. Lisboa: Fundação Calouste Gulbenkian, 1997.

CASSESE, Antônio. International criminal law. New York: Oxford University, 2003.

CÉSAIRE, Aimé. Discours sur le colonialisme. Paris: Présence Africaine, 1995.
CORTE INTERAMERICANA DE DIREITOS HUMANOS. Caso Barrios Altos versus Peru. Julgamento de 14 de março de 2001. Disponível em: <http://www.corteidh. or.cr/docs/casos/articulos/Seriec_75_esp.pdf>. Acesso em: 23 mar. 2016.

CORTE INTERAMERICANA DE DIREITOS HUMANOS. Caso Gomes Lund e outros ("Guerrilha Do Araguaia") vs. Brasil. Julgamento de 24 de novembro de 2010. Disponível em: <http://www.corteidh.or.cr/docs/casos/ articulos/seriec_219_por.pdf>. Acesso em: 15 ago. 2015.

CORTE INTERAMERICANA DE DIREITOS HUMANOS. Caso La Cantuta versus Peru. Julgamento de 29 de novembro de 2006. Disponível em: <http://www.corteidh.or.cr/docs/casos/articulos/seriec_162_esp.pdf > . Acesso em: 23 mar. 2016.

FERRO, Marc. O livro negro do colonialismo. Tradução de Joana Angélica D’Ávila Melo. Rio de Janeiro: Ediouro, 2004.

GARAPON, Antoine. Peut-on réparer l'histoire? colonisation, esclavage, shoah. Paris: O. Jacob, 2008.

GOLDMAN, Robert. Amnesty laws and international law: a specific case. In: SEMINAR ON JUSTICE NOT IMPUNITY, Annals... Geneva: ICJ, 1992.

HOWARD-HASSMANN, Rhoda E.; LOMBARDO, Anthony P. Framing reparations claims: differences between the african and jewish social movements for reparations. African Studies Review, Cambridge, v. 50, n. 1, p. 27-48, Apr. 2007.

HUMAN RIGHTS WATCH. Historic moment in the fight to ensure there are no safe havens for mass killers. June 30, 2003. Available in: <https://www.hrw.org/ news/2003/06/30/historic-moment-fight-ensure-thereare-no-safe-havens-mass-killers>. Access: Mar. 22, 2016.

LAFER, Celso. A reconstrução dos direitos humanos: um diálogo com o pensamento de Hannah Arendt. São Paulo: Companhia das Letras, 1988.

MARTIN-CHENUT, Kathia. Introduction. In: MARTIN-CHENUT, Kathia; ABDELGAWAD, Elisabeth Lambert. Réparer les violations graves et massives des droits de l'homme: la Cour Interaméricaine, pionnière et modèle? Paris: Société de Legislation Compare, 2010.

MPF denuncia coronel Ustra por morte de militante comunista em 1972. O Globo, Rio de Janeiro, 27 ago. 2015. Disponível em: <http://oglobo.globo.com/brasil/mpf-denuncia-coronel-ustra-por-morte-de-militante-comunista-em-1972-17321904>. Acesso em: 22 mar. 2016.

ORGANIZAÇÃO DAS NAÇÕES UNIDAS. Convenção sobre a Imprescritibilidade dos Crimes de Guerra 
e dos Crimes Contra a Humanidade. 1968. Disponível em: $\quad<$ http://www.direitoshumanos.usp.br/index.php/ Sistema-Global.-Declara\%C3\%A7\%C3\%B5es-e-Tratados-Internacionais-de-Prote $\% \mathrm{C} 3 \% \mathrm{~A} 7 \% \mathrm{C} 3 \% \mathrm{~A} 3 \mathrm{o} / \mathrm{con}$ vencao-sobre-a-imprescritibilidade-dos-crimes-de-guerra-e-dos-crimes-contra-a-humanidade.html>. Acesso em: 22 mar. 2016.

PERRONE-MOISÉS, Cláudia. O perdão e os crimes contra a humanidade: um diálogo entre Hannah Arendt e Jacques Derrida. In: CORREIA, Adriano (Org.). Hannah Arendt e a condição humana. Salvador: Quarteto, 2006, p. 222.

PINHEIRO, Paulo Sérgio. O passado não está morto: nem passado é ainda. In: DIMENSTEIN, Gilberto. Democracia em pedaço: direitos humanos no Brasil. São Paulo: Companhia das Letras, 1996.

PLESSIS, Max Du. Historical injustice and international law: an exploratory discussion of reparation for slavery. Human Rights Quarterly, Maryland, v. 25, n. 3, p. 624659, Aug. 2003.

SHELTON, Dinah. The world of atonement: reparations for historical injustices. Netherlands International Law
Review, Cambridge, v. 50, p. 289-325, 2003.

SIKKINK, Kathryn. Human rights, principled issue-networks, and sovereignty in Latin America. International Organization, Cambridge, v. 47, n. 3, p. 411-441, Summer, 1993.

TODOROV, Tzvetan. A conquista da América: a questão do outro. Tradução Beatriz Perrone-Moisés. 3. ed. São Paulo: M. Fontes, 2003.

TRINDADE, Antônio Augusto Cançado. Tratado de direito internacional dos direitos humanos. Porto Alegre: S.

A. Fabris, 1997.

UNITED NATIONS. Report of the World Conference against Racism, Racial Discrimination, Xenophobia and Related Intolerance. Durban, Aug./Sept. 2001. Available at: <http://www.un.org/WCAR/aconf189_12.pdf>. Access: Mar. 22, 2016.

UNITED NATIONS. Question of the impunity of perpetrators of human rights violations (civil and political): final report prepared by Mr. Joinet pursuant to Sub-Commission decision 1996/119. June 1997. Available at: <http:// www.refworld.org/docid/3b00f1a124.html>. Access: Mar. 22, 2016.

VUCKOVIC, Nadja. Quem pede reparações, e por quais crimes. In: FERRO, Marc (Org.). O livro negro do colonialismo. Tradução de Joana Angélica D’Ávila Melo. Rio de Janeiro: Ediouro, 2004. 